\title{
Predicting climate change effects on agriculture from ecological niche modeling: who profits, who loses?
}

\author{
Jan Beck
}

Received: 12 October 2010 / Accepted: 22 April 2012 / Published online: 12 May 2012

(C) Springer Science+Business Media B.V. 2012

\begin{abstract}
The susceptibility of agriculture to changing environmental conditions is arguably the most dangerous short-term consequence of climate change, and predictions on the geography of changes will be useful for implementing mitigation strategies. Ecological niche modeling (ENM) is a technique used to relate presence records of species to environmental variables. By extrapolation, ENM maps the suitability of a landscape for the species in question. Recently, ENM was successfully applied to predict the geographic distribution of agriculture. Using climate and soil conditions as predictor variables, agricultural suitability was mapped across the Old World. Here, I present analogous ENM-based maps of the suitability for agriculture under climate change scenarios for the year 2050. Deviations of predicted scenarios from a current conditions model were analyzed by (1) comparing relative average change across regions, and (2) by relating country-wide changes to the data indicative of the wealth of nations. The findings indicate that different regions vary considerably in whether they win or lose in agricultural suitability, even if average change across the entire study region is small. A positive relationship between the wealth of nations and change in agriculture conditions was found, but variability around this trend was high. Parts of Africa, Europe and southern and eastern Asia were predicted to be particularly negatively affected, while north-eastern Europe, among other regions, can expect more favorable conditions for agriculture. The results are presented as an independent "second opinion" to previously published, more complex forecasts on agricultural productivity and food supply variability due to climatic change, which were based on fitting environmental variables to yield statistics.
\end{abstract}

\section{Introduction}

Man-made climatic change is expected to have a variety of adverse consequences, among them an increase in extreme weather events (Easterling et al. 2000) and consequent impacts on economic and human health (Patz et al. 2005), or range shifts and extinction of species

Electronic supplementary material The online version of this article (doi:10.1007/s10584-012-0481-x) contains supplementary material, which is available to authorized users.

J. Beck $(\bowtie)$

Department of Environmental Science, Biogeography, University of Basel,

St. Johanns-Vorstadt 10, CH-4056 Basel, Switzerland

e-mail: jan.beck@unibas.ch 
(e.g., Parmesan and Yohe 2003; Chen et al. 2011) with potential consequences on biodiversity and ecosystem functioning (Balvanera et al. 2006). However, the arguably most important and immediate danger for human societies and economies will be the effects on the distribution and productivity of agriculture. Agriculture is closely tied to climatic conditions (Rosenzweig and Hillel 2008) and has largely determined the historical 'carrying capacity' of a region. Most populations were dependent on local or regional food production throughout history (e.g., Diamond 2006).

It is therefore not surprising that attempts at predicting the future of agriculture in a changing climate are manifold and that they have been received with great interest (e.g., Adams et al. 1990; Rosenzweig and Parry 1994; Olesen and Bindi 2002; Parry et al. 2004; Fischer et al. 2005). These often complex models took into account many different economical and agricultural variables. Most relevant here, most past studies modeled agricultural productivity as functions of the environment that have been fitted to yield data for the most important crop plants (i.e., cereals).

Techniques of ecological niche modelling (ENM, also termed 'species distribution modeling'; Elith and Leathwick 2009) may offer a quite different approach to relate agriculture to the environment. ENMs have been developed and successfully applied to estimate the geographic ranges of species from recorded presences on the basis of the environmental conditions encountered. By linking recorded presences with environmental conditions, the ecological niches of species are inferred (Soberon and Nakamura 2009). These niche models are then projected over rasterized environmental data to retrieve geographical predictions on the suitability of landscapes for the species, hence allowing a prediction of its occurrence. Beck and Sieber (2010) have recently borrowed this approach to model the suitability of agriculture in different regions based on climatic and soil conditions. They reported a relationship between their model of suitability for agriculture and human population density as well as regional economic strength. In their approach, Beck and Sieber (2010) used a broad spectrum of plant communities managed for food production in their definition of "agriculture" (i.e., differences in agricultural techniques and in crops utilized in different parts of the world were ignored), but they did not include 'high-tech' plant production (i.e., greenhouses, large-scale irrigation) and plantations of cash-crops (e.g., palm oil).

While the application of ENM to "agriculture" as a whole may be oversimplifying for some applications, it carries some advantages precisely due to this generality and simplicity. For example, it avoids the uncertainties involved in yield estimates and provides estimates that are independent from other published data, hence providing a "second opinion" to such dependent predictions.

In this paper, I applied an ENM of climate- and soil-driven suitability for agriculture (i.e., croplands) across the Old World and extrapolated it to different climate change scenarios for the year 2050. I mapped and quantified which regions will be "winning" and "losing", and further explored links of these patterns with population densities and with the wealth of countries. I compared effects on agriculture under two climate scenarios and discuss the results in the context of earlier studies that used other modeling approaches to address similar questions.

\section{Methods}

2.1 Modeling suitability for agriculture

290 presence records of agriculture across many ethnic groups and world regions (see Beck and Sieber 2010 for details and free access to data) were used to model the probability of occurrence 
of agriculture from current climatic and soil conditions across the Old World plus the Australia/ Pacific region $\left(25^{\circ} \mathrm{W}-180^{\circ} \mathrm{E}, 90^{\circ} \mathrm{N}-60^{\circ} \mathrm{S}\right)$. These data were assembled from descriptions of 'traditional' plant cultivation for food, i.e. excluding pastures, high-tech practices (e.g. nontraditional irrigation, greenhouses) and cash-crops such as coffee or palm oil. Sites were chosen irrespectively of what plants were cultivated there. I used data from Monfreda et al. (2008) to assign these presence points to main staple crop growing areas (assuming presence of a plant where yield values are given). According to this, $81 \%$ of presence points were in maizegrowing regions, $70 \%$ in rice regions, $61 \%$ in sweet potato regions, $54 \%$ in wheat regions, $29 \%$ in rye regions and $22 \%$ in yam regions (data add to more than $100 \%$ because at most sites more than one crop is grown). This reflects the large tropical extent of agriculture in the Old World. $12 \%$ of presence points, most of them from Africa, lay in regions where Monfreda et al. (2008) do not give yield data for any of the above plants.

Current climate data (in $2.5^{\prime} \times 2.5^{\prime}$ lat/long $\approx 5 \times 5 \mathrm{~km}$ resolution) were taken from www.worldclim.org (accessed June 2010), whereas I rasterized a soil classification from the Food and Agriculture Organization (FAO; http://www.fao.org/ag/agl/agll/wrb/soilres.stm; accessed June 2010) in the same resolution (latest FAO classification, 32 soil types). 17 'bioclimatic' variables (see Supplement for details) and 'soil type' were used for the ENM.

The maximum entropy method (Maxent; Phillips et al. 2006; Phillips \& Dudik 2008) was used to quantitatively relate the presence of agriculture to environmental conditions and to obtain estimates of the probability of occurrence of agriculture for each raster cell. Maxent is considered among the best currently available techniques of ecological niche modeling (Elith et al. 2006). Beck and Sieber (2010) had tentatively termed this output "suitability" for agriculture. The predictive ability of the model was evaluated by fitting the model to a random selection of $75 \%$ of records while using the remaining $25 \%$ as independent 'test data'. This procedure was repeated 10 times to retrieve mean values of model quality. At each run, model performance was measured on 'test data' according to a standard metric, the area under the receiver-operating characteristic (AUC; Marzban 2004). An AUC close to one indicates minimal errors (both omission and commission), whereas an $\mathrm{AUC}=0.5$ would be expected from a random prediction. For further analysis, however, a model run containing all data was used. This model was almost identical to the model of Beck and Sieber (2010).

\subsection{Climate change predictions}

Various global circulation models (GCMs) are used in climatology. All of these models attempt to describe the mechanistic links of variables that govern global climate and allow prediction on what will happen under certain assumptions of change (e.g., elevated $\mathrm{CO}_{2}$-levels). There is no consensus on which model is most accurate (IPCC 2001). Results based on the CCCMACGCM2 model are presented here, but all analyses were repeated for three further models for which data were available, i.e. NIES99, CSIRO-MK2.0 and UKMO-HADCM3. These data are presented as a Supplement, whereas only major deviations from data shown here are highlighted. The Intergovernmental Panel on Climate Change (IPCC) has defined various political and economic scenarios that are frequently used for deriving climate change predictions. Data for two of these scenarios were used here. Scenario A2a can be labeled as 'pessimistic' (national/ regional economic interests followed, fast-growing population, slow and fragmented technological change), whereas B2a is more 'optimistic' (national/regional economic, social and environmental interests followed, slower population growth, slow and fragmented technological change; see Special Report on Emissions Scenarios, IPCC 2001, for details). Predictions for these scenarios for the year 2050 (data from http://www.ccafs-climate.org/; accessed June 2010) were used, in combination with the ENM of agriculture (fitted to current conditions, see above), 
to derive a projection of agricultural suitability for the future (soil type was kept as a nonchanging variable).

\subsection{Data analysis}

Climate change effects on the suitability of agriculture were calculated as the difference between a future scenario and the current conditions model (i.e., positive values denote better conditions in the future, while negative values indicate worsening conditions). All raster data manipulation and map editing was carried out in ArcGIS 9.2.

To quantify major patterns and relate them to other features of regions, values for 20'000 randomly chosen grid cells were extracted (data available as Supplement). Means for larger geographic regions were calculated, and values were related to population density (year 2005: http://gcmd.nasa.gov/records/GCMD_Landscan.html; accessed 2008; data per km², interpolation averages for the ca. $5 \times 5 \mathrm{~km}$ cells). Means were also aggregated by country and compared to per capita gross domestic product (GDP) of nations (data for 2005, http://geodata.grid.unep.ch/; accessed June 2010). These data were considered more relevant than cell-wide GDP data in the current context, as nations may be the unit of action and mitigation of regional climate change effects. All relevant analyses were repeated after including only regions where (current) suitability (i.e., modeled probability of occurrence) is $\leq 0.27$. In this data range, stronger links between agriculture and local population density were reported (Beck and Sieber 2010), and climate change effects may therefore have more direct effects on population carrying capacity. Additionally, change in suitability was tabulated by growing regions of major staple crops, defined by yield data in Monfreda et al. (2008).

Beck and Sieber (2010) had speculated that ENM output may be positively related to yield, which would increase the relevance of ENM data as presented here. While a detailed appraisal of this relationship is pending, I used summed yield data for the most important cereals (wheat, rice, maize and rye, year 2000; Monfreda et al. 2008, data available at http:// www.sage.wisc.edu/mapsdatamodels.html; accessed August 2010) and correlated it to ENM "suitability" for agriculture.

\section{Results}

Figure 1 shows the model output for agriculture suitability under current conditions (i.e., averages 1950-2000). A model test on $25 \%$ of data yielded an $\mathrm{AUC}=0.860$ (mean of 10 runs), indicating good predictive performance. The two most important input variables were annual precipitation and annual temperature range, whereas soil type was the third most important variable (see Supplement for model details and response curves).

Figures 2 and 3 map predicted suitability and deviations from current conditions for the year 2050 (scenarios A2a and B2a, respectively). Across the entire region, all models except NIES99 predicted a slight mean decrease in future suitability (for CCCMA: mean $\pm 99 \% \mathrm{CI}=-0.005 \pm$ 0.002 for A2a, $-0.005 \pm 0.001$ for B2a; see Supplement for other models). However, variation around this mean loss was high and showed a strong geographic structure. Some regions benefit considerably, while others lose.

Densely populated cells lost more than sparsely populated cells sites (data not shown), but the link was very weak $\left(\mathrm{r}^{2}<0.08\right.$ for linear regression on log-transformed population density). The pattern got even weaker $\left(r^{2}<0.01\right)$ if restricted to those sites where strong relationships with population density were expected (i.e. where current suitability was $\leq 0.27$; Beck and Sieber 2010). 


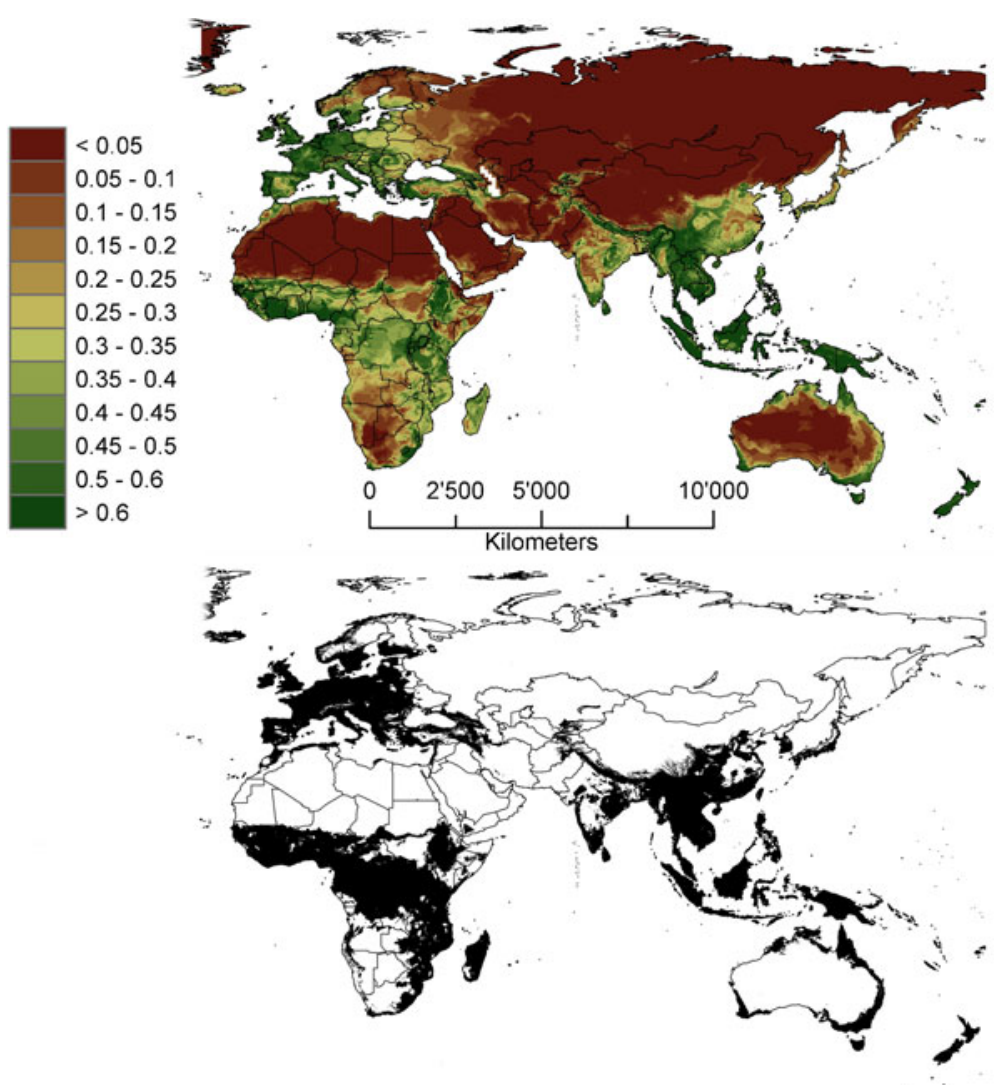

Fig. 1 Upper map: Modeled suitability for agriculture under current climatic conditions ("probability of occurrence", theoretically ranging from 0 to 1 ). Lower map: Regions where current modeled suitability is $>0.27$ (in black). Below that value (i.e., in the white terrestrial areas), Beck and Sieber (2010) showed a steep relationship between agriculture suitability and (log-)population density, whereas it was much more shallow above

A summary of expected changes by geographic regions is presented in Fig. 4. Some regions, such as Eastern Europe, were predicted to benefit on average from climate change, whereas other, such as West Africa, will have poorer conditions. Excluding regions where suitability is probably less directly related to population density (i.e., current suitability $>0.27$ ) confirmed some, but modified other assessments. The Arabian Peninsula, for example, benefited overall, but regions with already relatively poor conditions lost out. Western Europe benefited only slightly overall, but did so strongly in those regions currently judged poor for agriculture.

Figure 5 relates per capita GDP, as a measure of nations' wealth, to the country-wide mean modeled agricultural suitability change. A pattern of economically weak countries that lose more than rich countries emerged, but scatter was high and there were winners and losers across the entire range of GDP. Perhaps most relevant was a cluster of economically very weak countries from West Africa that were predicted to lose more agricultural suitability than the majority of other countries.

Maps of differences between agriculture suitability predictions for the two IPCC scenarios (A2a and B2a), and for the four circulation models used, are shown in the Supplement. 

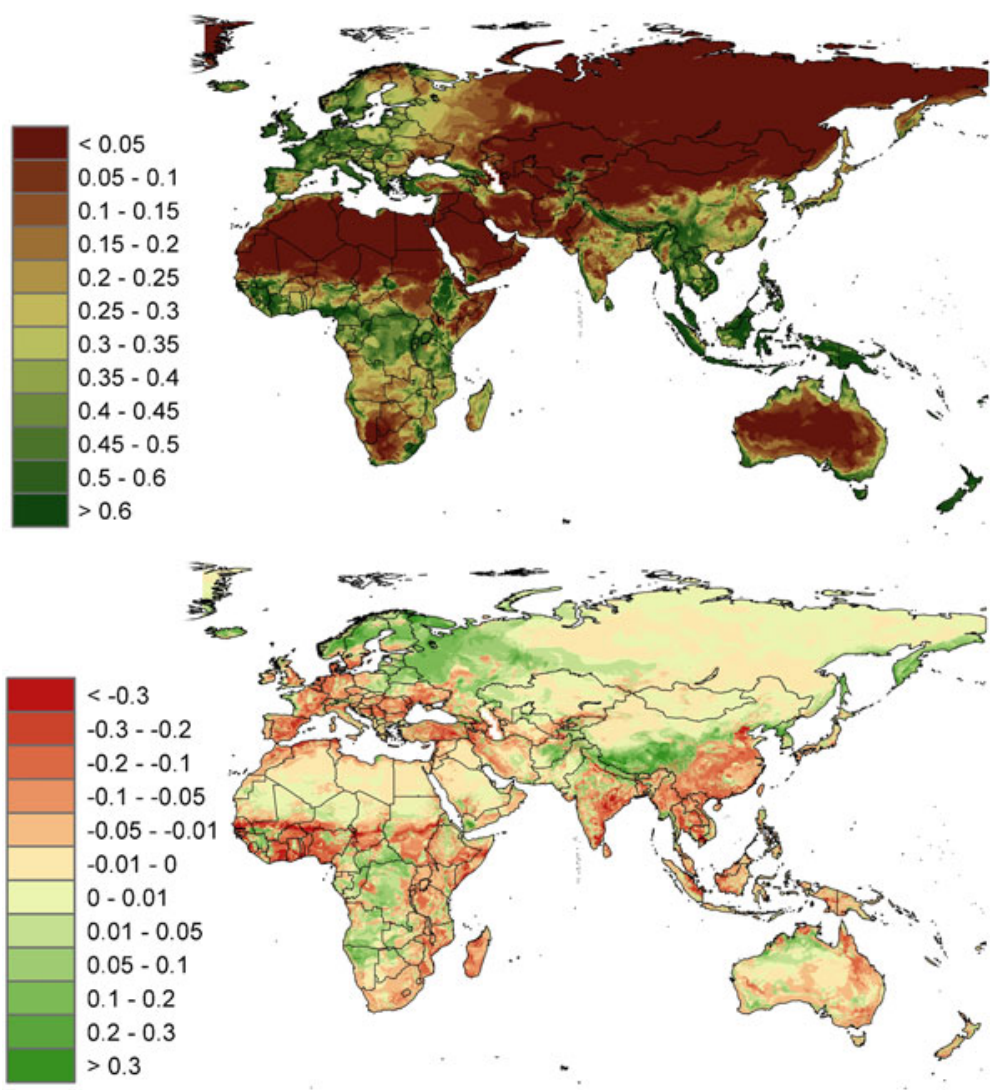

Fig. 2 Upper map: Modeled suitability for agriculture under the A2a scenario of climate change for the year 2050. Lower map: Modeled change between current (Fig. 1) and future conditions (i.e., change = A2a-current). Positive values denote better conditions, negative values indicate worsening

While there was some disagreement on whether agriculture in central Europe or central Africa, for example, would be better off under A2a or B2a scenarios, these comparisons broadly agreed where B2a should be preferred (e.g., in the Sahel or in the populous eastern part of China) and where not (e.g., Scandinavia and Eastern Europe).

When comparing mean projected changes of the growing regions of major staple crops (see Supplement), one can see a slight trend of larger losses in regions where tropical plants are grown (i.e., rice, sweet potato, yam), intermediate losses for wheat- and maize-growing regions, and almost no losses in rye-growing regions. This trend is confirmed if only data from the main growing regions for each crop (i.e., the $25 \%$ most productive sites) are considered. However, variation around these means is substantial (i.e., within growing regions there are local losses and gains). Furthermore, the described trends are of similar magnitude as, e.g., variation between GCMs. All data except rye under NIES99 indicate mean losses, and losses under A2a scenario are generally higher then under B2a.

A rank correlation of ENM-derived suitability (based on current climate) to available yield data indicated that ENM suitability is positively related to yield (Spearman $\mathrm{R}=0.53$ ). However, negative exponential regression smoothing (not shown) indicated that the relationship is non-linear, featuring (on $\log _{10}($ yield +1$)$-transformed data) a linear increase to a 

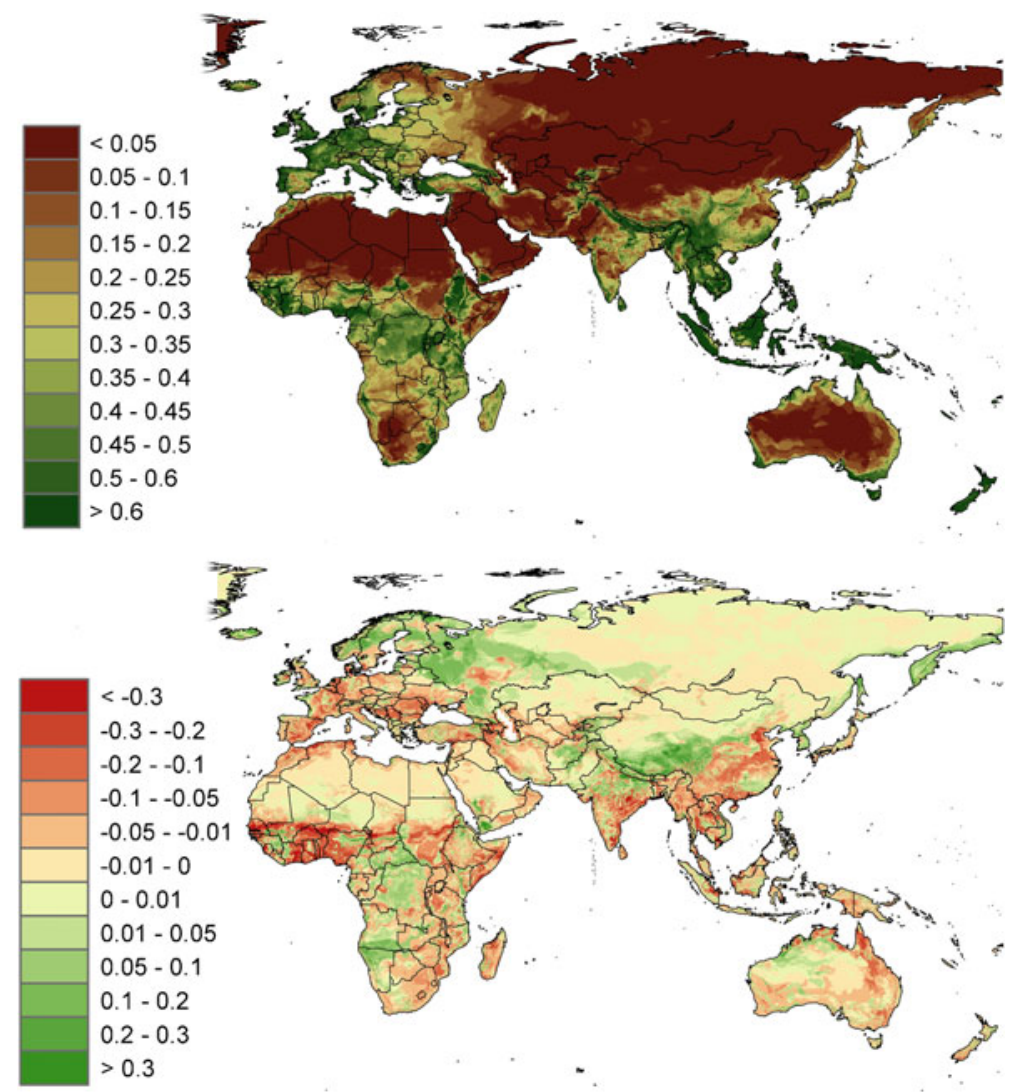

Fig. 3 Upper map: Modeled suitability for agriculture under the B2a scenario of climate change for the year 2050. Lower map: Modeled change between current (Fig. 1) and future conditions (i.e., change $=$ B2a-current). Positive values denote better conditions, negative values indicate worsening

suitability of ca. 0.27 (see above for coincidence of this threshold with other results) and no relationship above that values. Linear breakpoint regression according to this specifications explained ca. $27 \%$ of yield variability. I.e. ENM-derived "suitability" is a good predictor of current cereal yield for regions of poor (modeled) agriculture, whereas the two types of data are not closely related in agriculturally rich regions.

\section{Discussion}

\subsection{Caveats and advantages of niche model predictions}

Any prognosis of future events and conditions should be met with some skepticism. Despite best attempts, there are manifold potential sources of error in all predictive models, ranging from input data (e.g., climate change predictions; IPCC 2001) to technical issues (e.g., regarding the niche model approach taken here; Elith and Leathwick 2009; Soberon and Nakamura 2009; see also Beck and Sieber 2010) and interpretation. The response of soils to climate change, in particular their carbon and nutrient stocks (Smith et al. 2005; Quinton et al. 2010), and associated 
susceptibility to soil erosion is debated (van Oost et al. 2007; Lal and Pimentel 2008). Whatever the anticipated direction and rate of change, recent results suggest that soils in agricultural landscapes are far from steady (Quinton et al. 2010). Changes in agricultural practices may also mitigate changes in "suitability" (e.g. Mendelsohn and Dinar 1999; Smit and Skinner 2002), whereas future political and economic circumstances may lead to unexpected consequences of such change. However, due to modeling current agricultural practice as a whole in this study, results are probably robust to regional change of farming method whereas entirely new inventions are not likely to be used across the world in the time range treated here. As outlined in Methods, the majority of input data lay within the growing areas of the globally relevant staple crops.

Rare but extreme weather events may affect plant growth (Kreyling et al. 2010), whereas only climatic averages were considered here. Other modeling studies have tried to consider some of these possibilities by integrating, e.g., agricultural adaptation and changing trade patterns (Parry et al. 2004; Fischer et al. 2005). Likewise, direct effects of $\mathrm{CO}_{2}$ enrichment on plant growth were included in some prediction attempts (Parry et al. 2004) whereas their exact consequences on in situ plant growth remain an issue of debate (Ainsworth et al. 2008; Körner 2009). Furthermore, as with all modeling exercises, the ability to predict empirical patterns is no proof for correctly modeled causalities - but these are best for successful prediction

Fig. 4 Change in suitability for agriculture for larger geographic regions. Positive values denote better conditions, negative values indicate worsening. For both climate change scenarios data from all 20’000 sample cells ("all data) and data restricted to cells initially poor in suitability $(\leq 0.27)$ are shown (see main text and Fig. 1 for details)
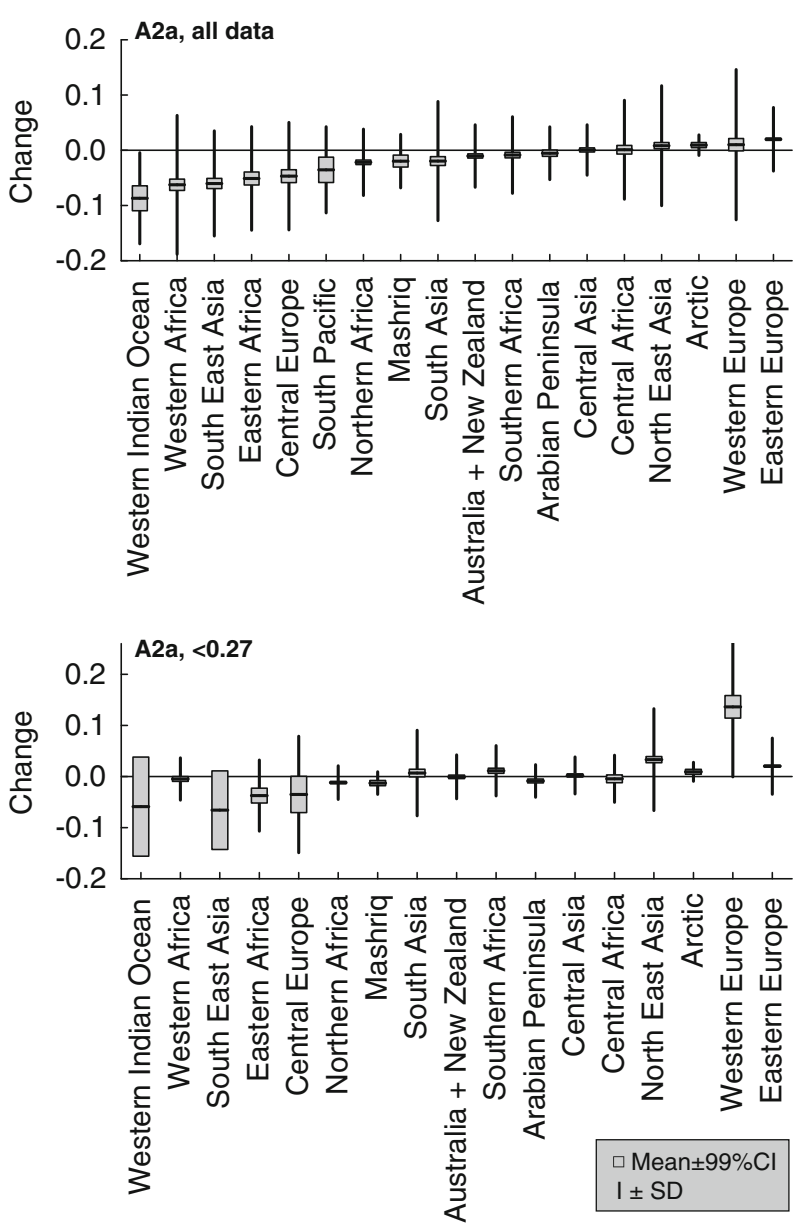
Fig. 4 (continued)
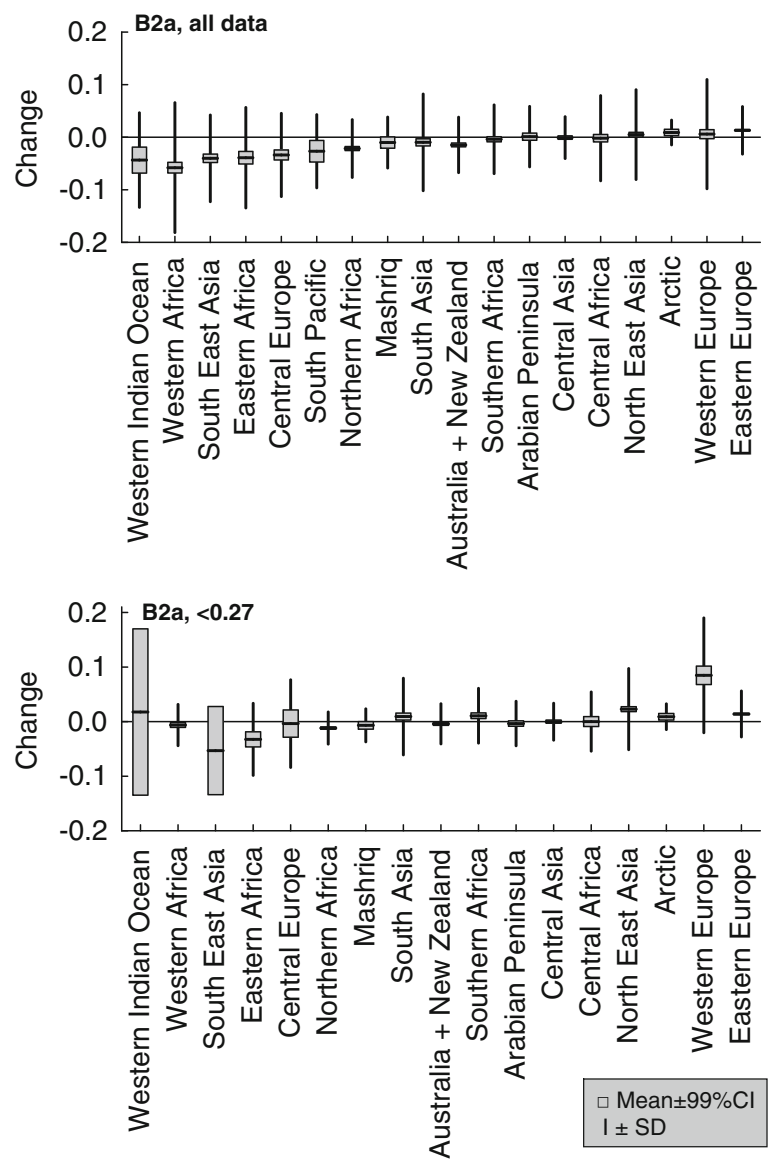

of new scenarios. In light of such uncertainties there is much value in employing and comparing a variety of methods (Araujo and New 2007), and data presented here should be understood as a complement to the existing, more sophisticated models of climate change effects.

ENM and future extrapolations thereof carry a number of problems and disadvantages that are discussed in detail with reference to modeling the occurrence of non-human species (e.g., Austin 2007; Elith and Leathwick 2009; Elith et al. 2010). These problems equally apply to applications of ENM to human populations (Samson et al. 2011) or human economic traits (Beck and Sieber 2010, this study). They include, e.g., that input occurrences may have been shaped by historical processes unrelated to the environmental variables in the model, the assumption of niche conservatism (here: no novel techniques), the neglected effects of potential interaction with other species (here: other economic activities that lead to acquiring food, i.e. trade), and they unknown capability of species to migrate fast enough to keep track of environmental change (here: speed of accepting techniques and crops from other regions). Similarly to species' range model predictions based on ENM, these limitations must be kept in mind when interpreting results, but they should not be a reason to discard ENM results. As pointed out below, earlier studies have addressed similar research topics on the basis of more detailed input data (i.e., yield statistics of selected crops) and more complex assumptions (e.g., $\mathrm{CO}_{2}$-effects, mitigation). Where data were presented in comparable fashion, they came to 
Fig. 5 Relationship between the wealth of countries (as per capita gross domestic product, GDP) and average predicted change in agricultural suitability in 2050 . GDP data from 2005 was available for 124 countries. Positive correlations between $\log _{10}$-transformed GDP and change left much variation unexplained $\left(r^{2}=0.054\right.$ for scenario A2a; $r^{2}=0.045$ for B2a) despite being statistically significant $(p<0.02)$. Data are available as Supplement. Locally weighted smoothing (not shown) confirmed that data can reasonably be represented by linear regression; i.e., there was no indication for different relationships between GDP and suitability change among poor or wealthy countries, respectively
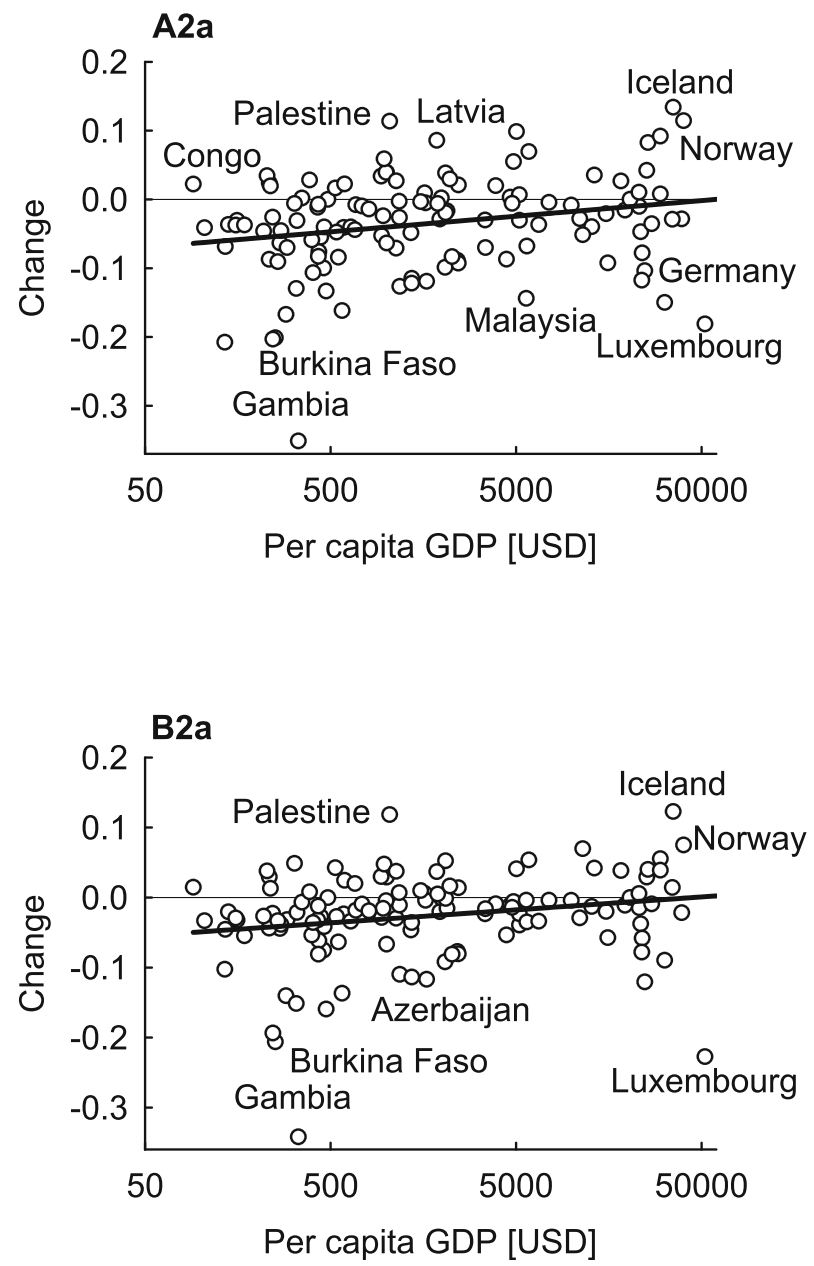

largely similar conclusions, which reaffirms both approaches and therefore lends credibility to those future projections. Furthermore, ENM data could be shown to be related to cereal yield (see above) and human population density (Beck and Sieber 2010) particularly for regions of low modeled suitability (i.e., $\leq 0.27$ ), which lends additional support to those analyses based on data from these regions alone.

\subsection{Winners and losers}

Results indicated, consistent with earlier projections, that there will be a slight decrease in mean conditions for agriculture across the modeled region. However, variation around this average change is large, has a strong geographical structure, and is hence much more relevant than the mean itself. Some modeled changes presented in this paper have long been predicted, such as the worsening conditions in the Sahel region south of the Sahara desert (IPCC 2001). Others are contrary to commonly perpetuated opinions (e.g., better conditions in central Europe; see also Parry et al. 2004 for ambivalent prediction in that region) 
or draw attention to patterns that have rarely, if ever, been discussed (e.g., better agriculture on the Tibetan plateau, which may have cultural and political implications). However, sensitivity analysis of replicate models indicated regions of particular model uncertainty in parts of Siberia and central Asia (see Supplement for map).

Samson et al. (2011) have taken a methodologically similar approach to map the vulnerability of human populations to climatic changes. As a notable difference, they directly used population density as a response to climatic variables whereas the model presented here implies that effects on humans are mediated mainly by effects on agriculture. When comparing their predicted changes of population carrying capacity (i.e., Fig. 4 in Samson et al. 2011) with predicted change in agricultural suitability in this study, major differences are only seen in parts of West Africa (Samson et al. 2011 do not predict the massive deterioration of conditions) and the Congo region (where Samson et al. 2011 are more pessimistic than this study). Zhang et al. (2011) provide data underpinning the causal relationships between climate, agriculture and human population density.

Various earlier studies related crop yields to climate and used these relationships to predict change for parts of the regions treated here. Only some of these studies can be reasonably compared to results presented here, showing detailed maps for some overall effect (i.e., treating not only specific crops). Predictions by Fischer et al. (2005) for cereal output in Africa in 2080 closely match predictions in this study. Main deviations from this study (Figs. 2 and 3) are less dramatic effects in (coastal) West Africa in Fisher et al. (2005) and a decline in output in northern Namibia. Rosenzweig \& Parry (1994) and Parry et al. (2004) made nation-wide predictions of cereal production which are consistent, in broad pattern, to data presented here. However, low spatial resolution and the inclusion of assumed $\mathrm{CO}_{2}$-effects make further comparison difficult.

A weakly positive link between countries' wealth and modeled change was found in this study (Fig. 5). This links with results in Samson et al. (2011), who found a negative relationship between per capita $\mathrm{CO}_{2}$ emissions and an index devised to measure vulnerability to climate change in the light of demographic processes. In combination these results support the notion that those who cause climate change (and get wealthy from industrialization) will have to suffer least from its consequences. However, in both studies data variation was high. In data presented here (Fig. 5), there are both rich and poor countries that are predicted to win or lose from climate change. A notable cluster of economically weak West African countries are predicted to suffer particular losses in agricultural suitability, which may influence economic and political developments in the region.

When comparing projected change of suitability in growing regions of major staple crops, the slightly negative averages (more pronounced in tropical crop plants) were associated with large variability around these averages. They imply that much of the locally expected losses in harvest of a particular crop could be mitigated by harvest benefits at some other location (if free exchange is feasible).

Our approach of modeling agriculture as a whole implies local variation of practices and therefore local adaptation (within the range of current practices), but it does not allow making specific predictions on site-specific crop exchanges. Crop-specific ENMs may be a suitable approach to explore such options. Global strategies of maintaining food availability under constraints of changing demography, climate and landuse have recently been discussed by Foley et al. (2011). However, the prospects of adaptation and mitigation in the timeframe discussed here may not only depend on what is scientifically possible, but also on the less optimistic outlook on overcoming selfish economic systems, poor leadership and irrational decisions (Diamond 2006; Dickinson 2009). 
Current agriculture, cultural history, national poverty, population density and -growth, carrying capacity, future environmental trends, and the abilities of cultural, economic and social structures to adapt, are interlinked in complex ways. Disentangling causalities and consequences for patterns presented here are well beyond the scope of this paper. Effects of change are probably most immediate in those regions of currently relatively poor conditions (cf. Fig. 4), as we may expect more direct effects on the local population carrying capacity (Beck and Sieber 2010). Parts of East Africa (i.e., northern Kenya, Somalia, parts of Ethiopia and southern Sudan) may deserve particular attention with regard to the mitigation of change (which seems to be supported by the 2011 food crisis in the region). Famine and regionalscale migrations have in the past led to violent conflict (Reader 1998; Beck 2011; Zhang et al. 2011), and such problems may be expected to increase in light of the modeled change scenarios.

In conclusion, ENM is a relatively simple approach that is less dependent on detailed data on agricultural practices and productivity, yet reproduces many patterns of climate change effects that had been previously published while deviating in some other aspects. As outlined above, reaching consensus by a variety of methodologies is a guard against the manifold error possibilities inherent to predicting the future.

Acknowledgements W. Schwanghart and M. Curran provided valuable comments on an earlier draft of the manuscript. M. Curran helped with the English presentation, L. Ballesteros with some aspects of modeling. Earlier work in collaboration with A. Sieber provided necessary raw data for this study. The study is part of a project funded by the Swiss National Science Foundation (SNF Grant 31003A_119879).

\section{References}

Adams RM, Rosenzweig C, Peart RM, Ritchie JT, McCarl BA, Glyer JD, Curry RB, Jones JW, Boote KJ, Allen JH Jr (1990) Global climate change and US agriculture. Nature 345:219-224

Ainsworth EA, Beier C, Calfapietra C, Ceulemans R, Durand-Tardif M, Farquhar GD, Godbold DL, Hendrey GR, Hickler T, Kaduk J, Karnosky DF, Kimball BA, Körner C, Koornneef M, Lafarge T, Leakey ADB, Lewin KF, Long SP, Manderscheid R, Mcneil DL, Mies TA, Miglietta F, Morgan JA, Nagy J, Norby RJ, Norton RM, Percy KE, Rogers A, Soussana JF, Stitt M, Weigel HJ, White JW (2008) Next generation of elevated $\mathrm{CO}_{2}$ experiments with crops: a critical investment for feeding the future world. Plant Cell Environ 31:1317-1324

Araujo MB, New M (2007) Ensemble forecasting of species distributions. Trends Ecol Evol 22:42-47

Austin MP (2007) Species distribution models and ecological theory: a critical assessment and some possible new approaches. Ecol Model 200:1-19

Balvanera P, Pfisterer AB, Buchmann N, He J-S, Nakashizuka T, Raffaelli D, Schmid B (2006) Quantifying the evidence for biodiversity effects on ecosystem functioning and services. Ecol Lett 9:1146-1156

Beck J (2011) Climate wars. Frontiers of Biogeography 3(3):84-85

Beck J, Sieber A (2010) Is the spatial distribution of mankind's most basic economic traits determined by climate and soil alone? PLoS One 5:e10416. doi:10.1371/journal.pone.0010416

Chen I-C, Hill JK, Ohlemüller R, Roy DB, Thomas CD (2011) Rapid range shifts of species associated with high levels of climate warming. Science 333:1024-1026

Diamond J (2006) Collapse. Viking Books, New York, 575 pp

Dickinson JL (2009) The people paradox: self-esteem striving, immortality ideologies, and human response to climate change. Ecol Soc 14(1):34

Easterling DR, Meehl GA, Parmesan C, Changnon SA, Karl TR, Mearns LO (2000) Climate extremes: observations, modeling, and impacts. Science 289:2068-2074

Elith J, Leathwick JR (2009) Species distribution models: ecological explanation and prediction across space and time. Annu Rev Ecol Evol Syst 40:677-697

Elith J, Graham C, Anderson R, Dudik M, Ferrier S, Guisan A, Hijmans R, Huettmann F, Leathwick J, Lehmann A, Li J, Lohmann L, Loiselle B, Manion G, Moritz C, Nakamura M, Nakazawa Y, Overton J, Peterson A, Phillips S, Richardson K, Scachetti-Pereira R, Shapire R, Soberon J, Williams S, Wisz M, 
Zimmermann N (2006) Novel methods improve prediction of species' distributions from occurrence data. Ecography 29:129-151

Elith J, Kearney M, Phillips S (2010) The art of modelling range-shifting species. Methods Ecol Evol 1:330-342 Foley JA, Ramankutty N, Brauman KA, Cassidy ES, Gerber JS, Johnston M, Mueller ND, O'Connell C, Ray DK, West PC, Balzer C, Bennett EM, Carpenter SR, Hill J, Monfreda C, Polasky S, Rockstrom J, Sheehan J, Siebert S, Tilman D, Zaks DPM (2011) Solutions for a cultivated planet. Nature 478:337-342

Fischer G, Shah M, Tubiello FN, van Velhuizen H (2005) Socio-economic and climate change impacts on agriculture: an integrated assessment, 1990-2080. Phil Trans R Soc B (Lond) 360:2067-2083

IPCC (2001) Climate Change 2001. Third Assessment Report. Complete online versions at http://www.grida.no/ publications/other/ipcc_tar/ (accessed June 2010)

Körner C (2009) Responses of humid tropical trees to rising $\mathrm{CO}_{2}$. Annu Rev Ecol Evol Syst 40:61-79

Kreyling J, Beierkuhnlein C, Jentsch A (2010) Effects of soil freeze-thaw cycles differ between experimental plant communities. Basic Appl Ecol 11:65-75

Lal R, Pimentel D (2008) Soil erosion: a carbon sink or source? Science 319:1040-1042

Marzban C (2004) The ROC curve and the area under it as performance measures. Weather Forecast 19:11061114

Mendelsohn R, Dinar A (1999) Climate change, agriculture, and developing countries: does adaptation matter? World Bank Res Obs 14:277-293

Monfreda C, Ramankutty N, Foley JA (2008) Farming the planet: II. Geographic distribution of crop areas, yields, physiological types, and net primary production in the year 2000. Global Biochemical Cycles 22:1-19

Olesen JE, Bindi M (2002) Consequences of climate change for European agricultural productivity, land use and policy. Eur J Agron 16:239-262

Parmesan C, Yohe G (2003) A globally coherent fingerprint of climate change impacts across natural systems. Nature 421:37-42

Parry ML, Rosenzweig C, Iglesias A, Livermore M, Fischer G (2004) Effects of climate change on global food production under SRES emission and social-economic scenarios. Glob Environ Change 14:53-67

Patz JA, Campbell-Lendrum D, Holloway T, Foley JA (2005) Impact of regional climate change on human health. Nature 438:310-317

Phillips SJ, Anderson RP, Schapire RE (2006) Maximum entropy modeling of species geographic distributions. Ecol Model 190:231-259

Phillips SJ, Dudik M (2008) Modeling of species distributions with Maxent: new extensions and a comprehensive evaluation. Ecography 31:161-175

Quinton JN, Govers G, van Oost K, Bardgett RD (2010) The impact of agricultural soil erosion on biogeochemical cycling. Nat Geosci 3:311-314

Reader J (1998) Africa. Biography of a continent. Penguin, London, 801 pp

Rosenzweig C, Hillel D (2008) Climate variability and the global harvest. Oxford University Press, Oxford, $259 \mathrm{pp}$

Rosenzweig C, Parry ML (1994) Potential impact of climate change on world food supply. Nature 367:133-138

Samson J, Berteaux D, McGill BJ, Humphries MM (2011) Geographic disparities and moral hazards in the predicted impacts of climate change on human populations. Glob Ecol Biogeogr 20:532-544

Smit B, Skinner MW (2002) Adaptation options in agriculture to climate change: a typology. Mitig Adapt Strateg Glob Chang 7:85-114

Smith J, Smith P, Wattenbach M, Zaehle S, Hiederer R, Jones RJA, Montanarella L, Rounsevell MDA, Reginster I, Ewert F (2005) Projected changes in mineral soil carbon of European croplands and grasslands, 1990-2080. Glob Change Biol 11:2141-2152

Soberon J, Nakamura M (2009) Niches and distributional areas: concepts, methods, and assumptions. Proc Nat Acad Sci 106:19644-19650

van Oost K, Quine TA, Govers G, de Gryze S, Six J, Harden JW, Ritchie JC, McCarty GW, Heckrath G, Kosmas C, Giraldez JV, da Silva JVM, Merckx R (2007) The impact of agricultural soil erosion on the global carbon cycle. Science 318:626-629

Zhang DD, Lee HF, Wang C, Li B, Pei Q, Zhang J, An Y (2011) The causality analysis of climate change and large-scale human crisis. Proc Nat Ac Sci 108:17296-17301 